\title{
Correction to: Comparison of Vitamin B12, Vitamin D, and Folic Acid Blood Levels in Plumbism Patients and Controls in Eastern Iran
}

\author{
Omid Mehrpour ${ }^{1,2} \cdot$ Marzieh Modi $^{3} \cdot$ Borhan Mansouri $^{4} \cdot$ Namam Ali Azadi $^{5} \cdot$ Samaneh Nakhaee ${ }^{1}$. \\ Alireza Amirabadi ${ }^{1} \cdot$ Gholamreza Anaei-sarab $^{1} \cdot$ Farshad M. Shirazi $^{6} \cdot$ Stephanie T. Weiss $^{7}$
}

Published online: 21 May 2020

(C) Springer Science+Business Media, LLC, part of Springer Nature 2020

\section{Correction to: Biological Trace Element Research https://doi.org/10.1007/s12011-020-02119-6}

The original version of this article unfortunately contained mistakes.

- The name of "Namam Ali Azadi" is now corrected in the author group

- Fourth to seventh sentence of the Abstract section should be "The results indicated that the mean vitamin B12, vita$\min \mathrm{D}$, and folic acid levels for the case group were 517.3 $\pm 419.4 \mathrm{pg} / \mathrm{ml}, 25.1 \pm 10.8 \mathrm{ng} / \mathrm{ml}$, and $9.2 \pm 6.1 \mathrm{ng} / \mathrm{ml}$, respectively. Mean folic acid level in the case group was significantly lower than control group (Fisher exact test, $P$ $<0.001$ ), whereas the mean of the vitamin D levels at the case group was no significantly higher than the control

The online version of the original article can be found at https://doi.org/ 10.1007/s12011-020-02119-6

Borhan Mansouri

borhanmansouri@yahoo.com

1 Medical Toxicology and Drug Abuse Research Center (MTDRC), Birjand University of Medical Sciences, Birjand, Iran

2 Rocky Mountain Poison and Drug Safety, Denver Health \& Hospital Authority, Denver, CO, USA

3 Student Research Committee, Birjand University of Medical Sciences, Birjand, Iran

4 Substance Abuse Prevention Research Center, Health Institute, Kermanshah University of Medical Sciences, Kermanshah, Iran

5 Biostatistics Department, Faculty of Public Health, Iran University of Medical Sciences, Tehran, Iran

6 Arizona Poison and Drug Information Center, University of Arizona, Tucson, AZ, USA

7 Wake Forest School of Medicine Addiction Medicine Program, Winston-Salem, NC, USA group (Fisher exact test, $P=0.059$ ). Moreover, mean vitamin B12 levels were significantly different between the case and control groups (Fisher exact test, $P=0.009$ ). In the control group, three patients had folic acid below normal level $(<6 \mathrm{ng} / \mathrm{mL})$, while twelve subjects at case group had folic acid below normal level $(P<0.05)$. Also, none of the control group had low vitamin B12 concentrations (< $180 \mathrm{pg} / \mathrm{ml})$, while seven subjects of case group had vitamin B12 below normal level $(P<0.05)$."

- In page 6, Discussion part, 4th paragraph:

We found that mean blood folate levels in the lead-poisoned patients, who had a mean BLL of $66 \pm 37.3 \mu \mathrm{g} / \mathrm{dl}$, were significantly lower than in healthy subjects $(9.2 \pm 6.1 \mathrm{ng} / \mathrm{ml}$ vs. $12.70 \mathrm{pg} / \mathrm{ml})$. 